\title{
Caracterização do processo de análise do jogo em clubes da 1a liga portuguesa profissional de futebol na época 2005/ 2006
}

CDD. 20.ed. 796.073

796.33
Pedro Miguel SILVA*

J orge CASTELO** Pedro SANTOS ${ }^{* * *}$

\section{Resumo}

0 nivel competitivo alcançado pelo futebol profissional tem exigido niveis de desempenho cada vez mais elevados. Uma das formas que tem sido utilizada para monitorá-la é a análise do jogo (AJ). 0 presente trabalho pretendeu caracterizar o processo de $\mathrm{AJ}$ na $1^{\mathrm{a}}$ liga portuguesa profissional de futebol. Os objetivos do estudo foram conhecer: 1) a importância da AJ;2) a frequência da sua realização; 3 ) os profissionais envolvidos; 4) os instrumentos e métodos utilizados; e 5) a importância atribuída pelos treinadores a diferentes eixos de análise. A amostra foi constituída por 16 treinadores da $1^{\text {a }}$ liga portuguesa de futebol profissional 2005/2006 (89\% do universo em estudo). A cada um deles foi aplicado um questionário previamente validado por oito especialistas. Os resultados obtidos revelaram que a $\mathrm{AJ}$ adquire a sua pertinência ao nível da planificação tático-estratégica. É comumente utilizado um instrumento com categorias predefinidas e os eixos de análise eleitos estão relacionados com a dimensão tático-estratégica do jogo. 0 treinador principal é o protagonista na análise do jogo da sua equipe, delegando a função de análise dos adversários num profissional da equipe técnica. Os sistemas de análise utilizados não são sofisticados e apenas uma minoria admite recorrer à informática. Os eixos de análise menos valorizados estão relacionados com a análise energético-funcional dos jogadores. Sintetizando, na referida liga o processo de AJ é sistematizado e foca preferencialmente a vertente táctico-estratégica dos jogos analisados. No entanto, apesar de serem utilizados instrumentos com categorias predefinidas, os sistemas de análise utilizados são pouco sofisticado.

Unitermos: Futebol; Análise do jogo; "Scouting"; Desempenho; Modelo de jogo.

\section{Introdução}

Há muito que o futebol deixou de ser apenas um jogo. Atualmente, reúne o estatuto de atividade profissional altamente remunerada, estando ainda revestido de um crescente interesse comercial, político e social (Ali, 1988) altamente dependente da obtenção de sucesso. Este fato, acrescido dos interesses desportivos dos clubes, treinadores e jogadores, tem levado as equipes a perseguirem patamares máximos de rendimento, fazendo elevar consideravelmente o nível competitivo do futebol, a nível mundial.

Esta necessidade de jogar ao mais alto nível requer que os treinadores e clubes se dotem dos melhores meios existentes de melhoramento do desempenho (CARLING, 2001). Um dos aspetos fundamentais neste sentido, passa pela obtenção de informação pontual e objetiva sobre as atuações dos jogadores em competição (GARCía, 2000). Assim, os treinadores têm procurado obter informaçōes sobre o desempenho individual ou coletivo dos seus jogadores e equipes a partir da utilização de vários auxiliares de memória que vão desde o simples lápis e papel até à tecnologia de vídeo-computorização mais sofisticada (Franks, McGarry \& Hanvey, 1999). Neste contexto, a análise do jogo (AJ) é, atualmente, uma etapa imprescindível e fundamental do processo de preparação nos jogos coletivos (MoutinHo, 1991), sendo considerada de vital importância para a coleta de dados objetivos (Franks, 1997; GARGANTA, 2001).

Alguns autores advogam que a objetividade da informação recolhida depende, em grande parte, 
do grau de sistematização do processo de análise (Garganta, 1998, 2000, 2001; Hughes \& FranKs, 2004). No entanto, parece ser desconhecida a forma como é aplicado na prática aquilo que é teorizado na literatura científica. Esta lacuna inspirou a realização desta investigação, cujos objetivos foram traçados no sentido de: 1) conhecer a importância atribuída pelos treinadores à AJ; 2) verificar a frequência da sua realização; 3) averiguar quem são os profissionais

\section{Métodos}

\section{Amostra}

A amostra foi constituída por 16 treinadores da $1^{\text {a }}$ liga portuguesa de futebol profissional da época 2005/06 (quantidade correspondente a 89\% da população).

\section{Procedimentos}

Para a coleta de dados foi estruturado um questionário submetido à apreciação de oito especialistas. Para serem classificados como especialistas, estabeleceu-se como requisito mínimo que os indivíduos constituintes do painel de peritos fossem detentores de grau acadêmico em Ciências do Desporto.

Dos oito especialistas selecionados, quatro desempenhavam as funções de treinador há mais de cinco anos e os restantes quatro possuíam o grau de Doutor em Ciências do Desporto e lecionavam em universidades portuguesas.

O processo de validação foi realizado em quatro momentos diferentes, seguindo o mesmo tipo de procedimento utilizado por GARGANTA (1997):

1) Apresentação da primeira versão do questionário aos especialistas $\mathrm{A}$ e $\mathrm{B}$ e reformulação face às sugestões apresentadas;

2) Apresentação da segunda versão aos especialistas $\mathrm{C}$ e D e reformulação face às sugestôes apresentadas;

3) Apresentação da terceira versão aos especialistas $\mathrm{E}$ e $\mathrm{F}$ e reformulação face às sugestões apresentadas;

4) Apresentação da quarta versão aos especialistas $\mathrm{G}$ e $\mathrm{H}$ e reformulação final.

Após ter sido apresentado ao conjunto dos oito especialistas e reformulado nas diferentes questóes, o instrumento foi considerado validado.

O questionário foi constituído por 33 questôes de fácil compreensão e simples preenchimento das quais 29 eram questões de resposta fechada e quatro eram envolvidos no processo; 4) conhecer os instrumentos e métodos utilizados; e 5) conhecer a importância atribuída pelos treinadores a diferentes eixos de análise. Essencialmente, ao enveredar-se pela realização deste estudo, pretendeu-se conhecer a forma como os treinadores da $1^{\text {a }}$ liga portuguesa de futebol profissional compreendiam a AJ da sua equipe e a do adversário ("scouting”) e como a operacionalizavam nos seus clubes.

questôes de resposta aberta. Durante o processo de validação foram acrescentadas cinco novas questões ao questionário e nenhuma foi retirada. As questóes inicialmente apresentadas foram ainda reformuladas em aspectos considerados relevantes pelos especialistas.

Para o presente estudo, foram considerados os resultados de apenas 15 questóes. As restantes questôes, embora todas relacionadas com o processo de AJ nos clubes, traduziam resultados sobre tópicos importantes, mas que não se enquadravam com os objetivos da investigação. Das cinco novas questões acrescentadas, apenas uma foi utilizada no presente estudo. Essa questão pretendia averiguar a frequência do visionamento dos jogos em vídeo.

Relativamente às 15 questóes em análise, 14 eram de resposta fechada e uma questão era de resposta aberta. Das 14 questões de resposta fechada, em cinco o inquirido deveria assinalar "sim" ou "não". Em seis questôes deveria assinalar as opções adequadas à realidade do seu clube e em três questôes as respostas estavam organizadas numa escala de Likert de três pontos: 1 - pouco importante; 2 - importante; 3 muito importante.

Em quatro questôes de resposta fechada foi apresentada uma opção de resposta aberta na qual o inquirido podia especificar outra alternativa não contemplada no leque de opções para salvaguardar uma eventual omissão da resposta pretendida. Em duas questôes de resposta fechada, foi solicitado aos inquiridos que hierarquizassem as opções pelo grau de importância, correspondendo " 1 " à opção mais importante, " 2 " à segunda opção mais importante e assim sucessivamente.

A aplicação dos questionários foi realizada entre os meses de Julho de 2005 e Janeiro de 2006. Nos clubes em que o questionário não foi preenchido de forma presencial, a participação do treinador principal foi garantida por um administrador. 


\section{Análise estatística}

Os questionários recolhidos foram analisados no "software" SPSS v.14. Procedeu-se, inicialmente, à caracterização do estudo de cada uma das questões consideradas. A opção de resposta fechada presente na maioria das questôes eliminou a possibilidade da existência de "outliers" e não se registrou informação omissa relevante. Prosseguiu-se, então, com o estudo descritivo e exploratório dos dados com base na análise da média e da percentagem.

Para analisar as respostas às questôes estruturadas em escala de Likert, foram calculados os níveis médios de importância e considerados os seguintes intervalos:
- Mais de 50\% das respostas concentradas no ponto 1 (pouco importante) e um nível médio de importância inferior a 1,5 foram consideradas pouco importantes;

- Menos de 50\% das respostas concentradas em ambos os pontos 1 (pouco importante) e 3 (muito importante), ou níveis médios de importância iguais ou superiores a 1,5 e inferiores a 2,5 foram consideradas moderadamente importantes;

- Mais de 50\% das respostas concentradas no ponto 3 (muito importante) e um nível médio de importância igual ou superior a 2,5 foram consideradas muito importantes.

Estes critérios vêm ilustrados na TABELA 1.

TABELA 1 - Critérios utilizados para classificar as opções dos treinadores.

\begin{tabular}{lcccc}
\hline & $\mathbf{1}$ & $\mathbf{2}$ & $\mathbf{3}$ & Nível médio de importância \\
\hline Pouco importante & $>50 \%$ & $<50 \%$ & $<50 \%$ & $<1,5$ \\
Importante & $<50 \%$ & $\varepsilon 50 \%$ & $<50 \%$ & {$[1,5-2,5[$} \\
Muito importante & $<50 \%$ & $<50 \%$ & $>50 \%$ & $\varepsilon 2,5$ \\
\hline
\end{tabular}

\section{Resultados}

\section{Importância atribuída pelos treinadores à $\mathrm{AJ}$ dos adversários ("scouting") e das próprias equipes}

Os resultados mais importantes da TABELA 2 revelam que os treinadores consideram a informação decorrente do "scouting" muito importante para definir estratégias para superar os adversários $(2,69)$ e identificar os seus pontos fortes e fracos
$(2,63)$. O terceiro item mais importante foi a construção de exercícios de treino com base na informação do "scouting" $(2,13)$. Destaca-se ainda que vários treinadores utilizam essas informaçóes para proceder a alteraçóes ao nível do modelo de jogo $(50 \%$ dos treinadores consideram importantes ou muito importantes as informaçôes decorrentes do "scouting" para introduzir alteraçōes no jogo da sua equipe).

TABELA 2 - Ordenação decrescente da importância atribuída pelos treinadores à informação extraída da AJ do adversário.

\begin{tabular}{|c|c|c|c|c|}
\hline & \multicolumn{3}{|c|}{$\%$ de respostas $(n=16)$} & \multirow[b]{2}{*}{$\begin{array}{l}\text { Nível médio } \\
\text { de importância* }\end{array}$} \\
\hline & $\begin{array}{c}\text { (1) } \\
\text { Pouco } \\
\text { Importante }\end{array}$ & $\begin{array}{c}(2) \\
\text { Importante }\end{array}$ & $\begin{array}{c}\text { (3) } \\
\text { Muito } \\
\text { Importante }\end{array}$ & \\
\hline $\begin{array}{l}\text { Na definição da(s) estratégia(s) a utilizar para } \\
\text { superar o adversário }\end{array}$ & $0 \%$ & $31,3 \%$ & $0 \%$ & $31,3 \%$ \\
\hline $\begin{array}{l}\text { Na identificação dos pontos fortes e pontos } \\
\text { fracos do adversário }\end{array}$ & $0 \%$ & $37,5 \%$ & $0 \%$ & $37,5 \%$ \\
\hline Na construção de exercícios de treino & $25 \%$ & $37,5 \%$ & $25 \%$ & $37,5 \%$ \\
\hline $\begin{array}{l}\text { Na seleção do melhor sistema de jogo para jogar } \\
\text { com determinado adversário }\end{array}$ & $31,3 \%$ & $43,8 \%$ & $31,3 \%$ & $43,8 \%$ \\
\hline Na alteração da forma de jogar (Modelo de Jogo) & $50 \%$ & $37,5 \%$ & $50 \%$ & $37,5 \%$ \\
\hline
\end{tabular}

*Valores médios relativizados a uma escala de Likert de três Pontos: 1 - Pouco importante; 2 - Importante; 3 - Muito importante. 
A AJ da própria equipe (TABELA 3) foi considerada mais importante para: 1) consolidar a forma de jogar (modelo de jogo) $(2,94)$; 2) fornecer "feedback" à equipe e aos jogadores $(2,81) ; 3)$ identificar pontos fortes e fracos da equipe e dos jogadores $(2,75)$; 4) corrigir erros coletivos e/ou individuais $(2,75) ; 5)$ construir exercícios de treino $(2,69) ; 6)$ tornar o processo de treino eficaz $(2,69)$; e 7 ) definir os conteúdos do treino $(2,69)$. Podemos agrupar estes parâmetros em três tópicos principais reportando-se: 1) ao modelo de jogo; 2) à obtenção de "feedback"; e 3) à operacionalização do treino.

TABELA 3 - Ordenação decrescente da importância atribuída pelos treinadores à informação extraída da AJ da própria equipe.

\begin{tabular}{|c|c|c|c|c|}
\hline & \multicolumn{3}{|c|}{$\%$ de respostas $(n=16)$} & \multirow[b]{2}{*}{$\begin{array}{l}\text { Nível médio } \\
\text { de importância* }\end{array}$} \\
\hline & $\begin{array}{c}(1) \\
\text { Pouco } \\
\text { Importante }\end{array}$ & $\begin{array}{c}(2) \\
\text { Importante }\end{array}$ & $\begin{array}{c}\text { (3) } \\
\text { Muito } \\
\text { Importante }\end{array}$ & \\
\hline Na consolidação da forma de jogar (Modelo de Jogo) & $0 \%$ & $6,3 \%$ & $93,8 \%$ & 2,94 \\
\hline No "feedback" para a própria equipe e para os jogadores & $6,3 \%$ & $6,3 \%$ & $87,5 \%$ & 2,81 \\
\hline $\begin{array}{l}\text { Na identificação dos pontos fortes e pontos } \\
\text { fracos da equipe e dos jogadores }\end{array}$ & $0 \%$ & $25 \%$ & $75 \%$ & 2,75 \\
\hline $\mathrm{Na}$ correção de erros coletivos e/ou individuais & $0 \%$ & $25 \%$ & $75 \%$ & 2,75 \\
\hline $\mathrm{Na}$ construção de exercícios de treino & $12,5 \%$ & $6,3 \%$ & $81,3 \%$ & 2,69 \\
\hline $\mathrm{Na}$ eficácia do processo de treino & $6,3 \%$ & $18,8 \%$ & $75 \%$ & 2,69 \\
\hline Na definição dos conteúdos do treino & $0 \%$ & $31,3 \%$ & $68,8 \%$ & 2,69 \\
\hline No planeamento do treino & $12,5 \%$ & $43,8 \%$ & $43,8 \%$ & 2,31 \\
\hline Na estrutura da carga e recuperação (planeamento físico) & $25 \%$ & $31,3 \%$ & $43,8 \%$ & 2,19 \\
\hline No processo de recrutamento de jogadores para a equipe & $25 \%$ & $37,5 \%$ & $37,5 \%$ & 2,13 \\
\hline $\mathrm{Na}$ identificação de patamares de rendimento & $43,8 \%$ & $31,3 \%$ & $25 \%$ & 1,81 \\
\hline $\mathrm{Na}$ implementação de testes físicos & $75 \%$ & $12,5 \%$ & $12,5 \%$ & 1,38 \\
\hline No estabelecimento de picos de forma & $81,3 \%$ & $6,3 \%$ & $12,5 \%$ & 1,31 \\
\hline
\end{tabular}

\section{Frequência de realização da AJ da sua equipe e do "scoutings"}

Os resultados obtidos são reveladores da elevada valorização atribuída à $\mathrm{AJ}$ do adversário e da própria equipe. Registrou-se um valor de 93,8\% de treinadores que analisam todos os jogos da sua equipe. No que diz respeito ao "scouting", a totalidade dos treinadores alegou recolher informaçōes sobre os seus adversários.

No que diz respeito ao local do jogo, a maior parcela de treinadores analisa dois jogos do adversário a jogar em sua casa $(62,5 \%)$ e dois jogos do adversário a jogar fora de sua casa (50\%). Quanto ao número de vezes em que cada jogo do adversário é analisado com a ajuda do vídeo, os treinadores evidenciaram a preferência por 1 a 2 análises em vídeo.

\section{Profissionais envolvidos no processo de AJ da própria equipe e no "scouting"}

Na TABELA 4 são analisadas as preferências dos inquiridos na realização do "scouting" e da AJ das suas equipes. Verifica-se que os treinadores atribuem diferentes importâncias ao papel dos diversos elementos que realizam a $\mathrm{AJ}$ em função da direção da análise. Assim, a análise que o treinador realiza da sua equipe é considerada a mais importante $(87,5 \%)$, seguindo-se a que é levada a cabo pelo treinador adjunto $(43,8 \%)$. Para a realização do "scouting" observa-se que $43,8 \%$ dos treinadores inclui na sua equipe técnica um elemento exclusivamente com essas funçōes, seguindo-se ele próprio como o $2^{\circ}$ elemento prioritário (18,8\%). 
TABELA 4 - Primeira opção dos treinadores para a realização do “scouting” e da AJ da própria equipe.

\begin{tabular}{lcc}
\hline \multicolumn{1}{c}{ Opçóes } & “Scouting” & AJ própria equipe \\
\hline Treinador & $18,8 \%$ & $87,5 \%$ \\
Treinador adjunto & $25 \%$ & $43,8 \%$ \\
Outro elemento da equipe técnica & $0,0 \%$ & $18,8 \%$ \\
Um elemento da equipe técnica só com funções de AJ & $43,8 \%$ & $18,8 \%$ \\
Departamento de AJ* & $12,5 \%$ & $0 \%$ \\
Analista contratado e não pertencente ao clube & $12,5 \%$ & $6,3 \%$ \\
Outro: treinador adjunto da equipe de juniores do clube & $6,3 \%$ & -- \\
\hline
\end{tabular}

*Clubes com departamento de AJ - 43,8\%; Clubes sem departamento de AJ - 56,2\%.

\section{Instrumentos e métodos utilizados naAJ da equipe e no "scouting"}

Os resultados obtidos confirmam a utilização, pela maioria dos treinadores inquiridos $(62,5 \%)$, de um relatório padronizado com categorias predefinidas para analisar a sua equipe e o adversário. Existe, no entanto, um número considerável de treinadores que não possui nenhum instrumento de AJ predefinido, quer para o "scouting", quer para a AJ da sua equipe $(37,5 \%)$.

Em relação aos sistemas de AJ utilizados pelos treinadores, é consensual o recurso primeiramente à notação manual e/ou gravador de voz a partir de observação direta e, posteriormente, ao auxílio do vídeo, tanto no "scouting" como na AJ da sua própria equipe (68,8\% e 56,3\% respectivamente). Apenas 31,3\% dos treinadores recorrem ao computador e à utilização de um "software" esportivo para tratar a informação em ambas as situações. Três treinadores fizeram referência a esses "softwares":

- um Treinador utiliza dois programas de edição de vídeo;

- um Treinador utiliza um programa de edição de vídeo conjuntamente com um programa específico de análise do desempenho esportivo;

- um Treinador utiliza um programa desenvolvido pelo próprio analista de jogo.

\section{Eixos de AJ preferidos pelos treinadores}

Na TABELA 5 destacam-se a quantidade de itens que são considerados muito importantes para os treinadores: 1) identificação de padrōes de jogo e de variações (2,88 e 2,69, respectivamente); 2 ) análise de jogadas de bola parada contra $(2,88)$ e a favor $(2,81) ; 3)$ análise dos momentos de transição $(2,81$ em ambos os momentos de transição do ataque para a defesa e da defesa para o ataque); e 4) análise das ações ofensivas $(2,63)$ e defensivas $(2,56)$.

A caracterização individual dos jogadores, os parâmetros relacionados com a quantificação de dados, a análise das dimensões espaço e tempo e o comportamento do treinador adversário, embora tenham obtido valores intermédios de importância, foram considerados eixos de análise de menor importância em relação aos anteriores.

As distâncias percorridas pelos jogadores a alta, média, e baixa intensidade, assim como as distâncias totais percorridas, são os eixos de análise menos valorizados. Todos os parâmetros obtiveram níveis médios de importância correspondentes ao intervalo "pouco importante", à exceção do parâmetro de análise das distâncias percorridas pelos jogadores a alta intensidade. Neste parâmetro verificou-se um nível médio de importância de 1,56 que o coloca dentro do intervalo "importante". 
TABELA 5 - Ordenação decrescente da importância atribuída pelos treinadores a diversos eixos de AJ .

*Valores médios relativizados a uma escala de Likert de três Pontos: 1 - Pouco importante; 2 - Importante; 3 - Muito importante.

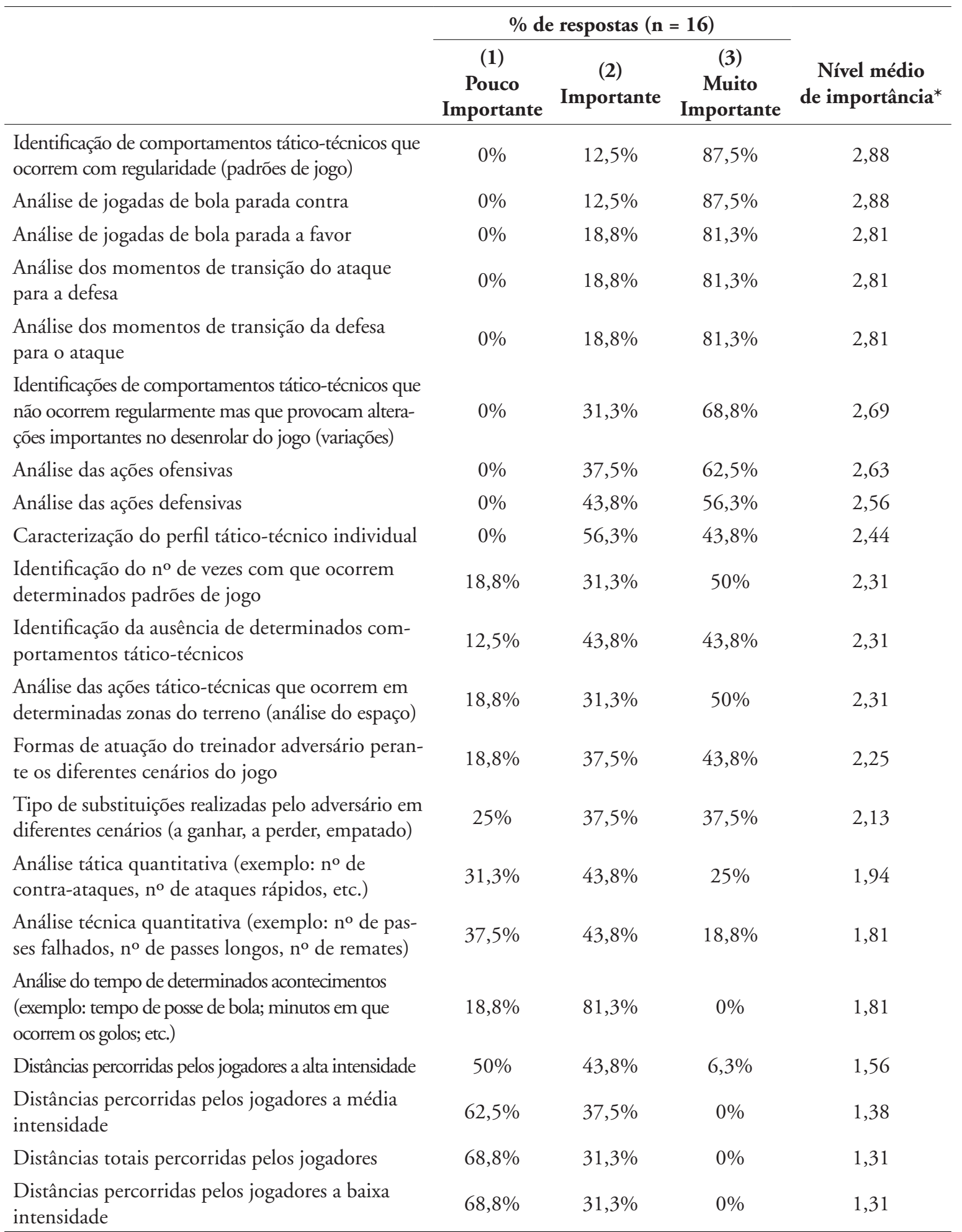




\section{Discussão}

Os resultados obtidos demonstram a importância do "scouting" para os treinadores da amostra na definição da abordagem tático-estratégica a desenvolver para o jogo. Foi evidenciada a busca de informações visando a definição de estratégias para superar o adversário e a identificação dos pontos fortes e fracos do mesmo. Na literatura esta ideia é igualmente suportada por vários autores (ARIEL, 1983; Carling, 2005; Garganta, 1998; Hughes \& Churchill, 2005; Lopes, 2005; Martins, 2000).

A construção de exercícios de treino com base na identificação de determinadas caraterísticas evidenciadas pelos adversários também parece ser conveniente tendo em conta que o treinador constrói, para o período semanal de treino, um conjunto de exercícios específicos que procuram simular a realidade da situação competitiva que a sua equipe irá vivenciar (CASTELO, 2004). Nesse sentido, a informação sobre o adversário deve nortear a construção de alguns exercícios de treino, nomeadamente os que se destinam a "ensinar" e a exercitar as soluçôes estratégicas delineadas para o jogo. Esta opinião também é corroborada pela maioria dos treinadores.

Uma questão relevante a ponderar reporta-se à profundidade com que as novas informações alteram a padronização dos exercícios utilizados assim como a forma de jogar. Os resultados obtidos na TABELA 2 relativos à importância atribuída pelos treinadores ao "scouting" para alterar a forma de jogar das suas equipes são discrepantes. Sendo o modelo de jogo uma conjetura de jogo (Oliveira, 2003) que se persegue e o orientador do todo o processo ensinoaprendizagem/treino (GARGANTA, 2003), parece-nos injustificável que os treinadores modifiquem aspectos do mesmo em função das caraterísticas do adversário a defrontar. Informaçōes sobre o adversário poderão ser oportunas na elaboração e reajuste dos exercícios de treino ao nível de uma padronização semanal. Contudo, o treinador não deverá abdicar da sua ideia de jogo devendo as alterações estratégicas introduzidas ser conscientes e refletidas. É aconselhável que essas alteraçóes sejam reguladas pelo modelo de jogo e pelos seus princípios organizativos.

Por outro lado, sendo a AJ da própria equipe com um determinado adversário uma forma de se obter informação relativamente à operacionalização do modelo de jogo (FrANKS \& MCGARRY, 1996), parece paradoxal que o mesmo seja alterado em função das caraterísticas desse adversário. Foi constatado que é consensual o recurso à informação decorrente da análise para aferir sobre a operacionalização da forma de jogar, tendo sido considerado, inclusivamente, o parâmetro mais importante. Esta valorização, em simultâneo, da consolidação de uma ideia de jogo e da sua alteração em função do adversário é incongruente. Tendo em conta estas informaçôes, é possível supor que, atualmente, numa altura em que o conceito de modelo de jogo é profusamente abordado no âmbito do treino, ainda existe muita confusão em redor do seu correto significado, sendo frequentemente confundido com o conceito de sistema de jogo. Este último diz respeito unicamente à disposição espacial dos jogadores no terreno de jogo (CASTELO, 2004) e mudanças a este nível não implicam, necessariamente, mudanças profundas nos princípios que dão corpo à ideia de jogo do treinador. Em todo o caso, é plausível admitir que os treinadores possam ter percebido a frase "alteração da forma de jogar” como uma modificação em menor proporção daquela que se pretendia transmitir no questionário. Neste sentido, a interpretação destes resultados deverá ter em consideração essa possibilidade.

Sendo o modelo de jogo um referencial que determina e dirige a forma como devem ser tratadas as diversas componentes do jogo (GARGANTA, 2000; Oliveira, 1991), a valorização concedida pelos treinadores à $\mathrm{AJ}$ das suas próprias equipes no sentido da sua consolidação é coerente, na medida em que se torna importante poder aceder à interpretação que é realizada pelos jogadores ao mesmo. Com base nessas informações é possível regular o treino, repetindo-se este processo após cada jogo disputado (FrANKS, GOODMAN \& Miller, 1983; Garganta, 1998; Hughes, 2005).

As informações da AJ que se relacionam com os parâmetros da obtenção de "feedback" foram também consideradas muito importantes, à semelhança do que é defendido na literatura. Diversos autores referem-se à utilização da AJ para identificação dos pontos fortes e fracos da equipe e para correção de erros coletivos e/ou individuais (GroOM \& Cushion, 2004; Hughes \& Churchill, 2005; Murtough \& Williams, 1999; Moutinho, 1991).

A informação fornecida aos jogadores sobre o seu próprio desempenho, num contexto coletivo ou individual (CALLIGARIS, MARELla \& INNOCENTI, 1990), é uma das variáveis mais importantes que influenciam a aprendizagem (FranKS \& MCGARRY, 1996; Garcia, 2000; Godinho, 2002; Hotz, 1999; Liebermann, Katz, Hughes, Bartlett, McClements \& Franks, 2002). A partir do 
reconhecimento dos aspectos que necessitam ser desenvolvidos ou reforçados, os treinadores podem planificar e organizar o treino tornando os seus conteúdos mais objetivos e específicos (SAMPAIO, 1999). Logo, é conveniente que a construção de exercícios tenha em conta as informações derivadas da análise de forma a que se intervenha cirurgicamente nos aspetos que requerem a atenção do treinador. Adapta-se, assim, o objetivo e a lógica do exercício à sua função específica, no que diz respeito à abordagem de um, ou mais, princípios do modelo de jogo que são perseguidos. Esta ideia é suportada por QueIROZ (1986) e CASTELO (2002).

Os resultados sobre a frequência da realização do "scouting" em função do local do jogo, reforçam a necessidade de analisar os adversários a jogar em casa e fora de sua casa. Nesta linha de pensamento, SiLVA (2002) estabelece relações entre o local do jogo e outros fatores relacionados (público, familiarização com o espaço, viagens) com o desempenho no futebol, apontando-o como influenciador dos estados psicológicos e comportamentais dos jogadores, treinadores e árbitros. No seu estudo com uma equipe participante na UEFA Champions League 2001/02, o mesmo autor verificou padrōes comportamentais diferentes em relação a diferentes indicadores táticos, consoante o jogo se disputava fora ou em casa da referida equipe. Deste modo, as opçóes manifestadas pelos treinadores inquiridos revelam-se oportunas se for considerado o fato de as equipes apresentarem sistemas, métodos e açôes estratégico-táticas diferentes, consoante os jogos se disputem no seu terreno ou no terreno das equipes que defrontam (PACHECO, 2005).

No que diz respeito à frequência de análises de cada jogo realizadas através do vídeo, as opções evidenciadas pela realização de uma a duas análises estão ajustadas, dados os constrangimentos temporais ao nível da coleta de dados e da sua posterior utilização na preparação para o jogo.

É pertinente a posição dos inquiridos de destacarem a análise que realizam das suas próprias equipes como sendo a mais importante. De acordo com Silva (1999) são os treinadores que assumem a responsabilidade na definição e implementação de uma concepção do jogo, logo, as suas opiniōes e ideias são fundamentais para esse entendimento. $\mathrm{O}$ treinador poderá e deverá recorrer a outras opiniōes para obter informações sobre o desempenho da sua equipe (os resultados apresentados na TABELA 4 apontam a opinião do treinador adjunto como a $2^{\text {a }}$ mais importante). Contudo, sendo ele próprio o protagonista na definição da forma como pretende que a sua equipe jogue, a sua própria análise revestese de especial importância.

O considerável número de treinadores que não utiliza nenhum tipo de instrumento de análise com categorias pré-definidas, não encontram as suas opçôes fundamentadas na literatura. Vários especialistas são da opinião que o resultado da análise depende das variáveis que estão a ser consideradas e da sua definição exata, pois estas ditarão a existência ou não de erros na recolha de dados (ANGUERA, VilLaseñor, López \& Mendo, 2000; Carosio, 2001; Contreras \& Ortega, 2000; García, 2000; Garganta, 2001; Olsen \& LaRsen, 1997; Rodrigues, 2004). Apesar de ser possível descrever inúmeros aspectos do desempenho de uma equipe, apenas uma série limitada de elementos são importantes (Franks, GoOdman \& Miller, 1983; Gowan, 1987), deste modo, é desejável conhecer previamente as categorias de análise (Carosio, 2001; Garganta, 2001, 2000, 1998).

No que diz respeito aos sistemas de AJ utilizados pelos treinadores, a maioria utiliza um método misto de observação (combinação da observação em tempo real e observação com manipulação do tempo), que é para Rocha (1996) o mais rigoroso e o que permite uma melhor identificação das caraterísticas que se procuram. Quanto ao grau de sofisticação dos sistemas utilizados, refira-se que face às novas tecnologias comercialmente existentes, os treinadores podem evitar o recurso a métodos tão morosos no processamento dos dados. Seria mais vantajoso a adoção de sistemas de análise mais sofisticados, nomeadamente ao nível dos sistemas computorizados com capacidade de manipulação da imagem digital. As vantagens da utilização deste tipo de sistemas são evidenciadas na literatura por autores como HugHES (1996, 1991) e RiERA (1995a).

Relativamente à seleção dos eixos de análise, a identificação de padróes de jogo visada pelos treinadores também é apontada por vários autores como importante no fornecimento de informação para aferir sobre os desempenhos observados e na regulação do processo de treino (FranKS, MCGARRY \& Hanvey, 1999; Garganta, 2001, 2000, 1998; Hughes \& Churchill, 2005; McGarRY \& Franks, 1994). Para além de padrōes, importa igualmente identificar acontecimentos que acontecem aleatoriamente e de forma imprevisível em determinadas configurações do jogo, produzindo alteraçôes significativas no mesmo. Neste contexto, os momentos de transição para o ataque e transição para a defesa são extremamente importantes (OlIVEIRA, 2004) pois reportam-se a períodos de tempo bastante curtos nos 
quais ambas as equipes se encontram momentaneamente desorganizadas para as novas funçôes que têm de assumir. Estes momentos do jogo adquirem maior pertinência se forem considerados os resultados da investigação de Pereira (2005). Este autor, baseado na análise de vários estudos, concluiu que 50\% dos golos em ação de jogo ocorrem em momentos de transição. Todas estas ideias são congruentes com as opçôes manifestadas pelos treinadores.

Relativamente à análise de jogadas de bola parada, as preferências dos treinadores também estão em conformidade com as opiniōes de CASTELO (1994) e CARLING (2005). Estes autores apontam este eixo de análise como um dos principais focos de interesse da AJ nos últimos anos.

Foi possível confirmar que a maioria dos treinadores considera ser útil a combinação de uma análise qualitativa (padrões de jogo) com uma análise quantitativa, sendo esta uma ideia igualmente reforçada por vários especialistas (GARCÍA, 2000; GARGANTA, 1998, 2000, 2001; MaIA, 2001; Morrison, 2000). Importa, contudo, fazer referência à valorização atribuída por vários treinadores a um tipo de análise puramente estatística e quantitativa, uma vez que esta é desaconselhada para tentar perceber a dinâmica de sistemas complexos como o futebol (BISHOVETS, Gadjiev \& Godik, 1991;Borrie, Jonsson \& MAgnusSON, 2002; EOM \& SCHUTZ, 1992; GARGANTA \& Gréhaigne, 1999; Gréhaign, Bouthier \& David, 1997; Grinvald, 1999; Hughes \& Bartlet, 2002; Jonsson, Bjarkadottir, Gislason, Borrie \& Magnusson, 2003; Joyce, 2002; Marques, 1995; Paulis \& MENDO, 2002), principalmente quando se centra numa análise quantitativa da técnica. Convocamos Garganta e Pinto (1998), Garganta
(2002), Castelo (2006) e Santos (2006) para argumentar que no futebol os fatores de execução técnica são sempre determinados por um contexto tático, tornando muito restrita a tentativa de compreensão do desempenho somente a partir do acesso à frequência de ocorrência de execuções técnicas.

A importância atribuída pelos treinadores à caracterização da atuação do treinador adversário também é reconhecida na literatura. CASTELO (1996) salienta que a partir do conhecimento do perfil do técnico adversário, o treinador prepara-se para a competição estabelecendo quais as respostas táticas mais rápidas, mais racionais e mais eficazes às questões formuladas por este e pela equipe adversária, durante a competição.

Os resultados registrados traduzem ainda que os treinadores preferem obter informação sobre as ações levadas a cabo pelos jogadores sob o ponto de vista tático nos diferentes momentos do jogo em vez de uma caracterização energético-funcional dos mesmos, tal como sugerem Grosgeorge, Dupuis e Vérez (1991). GARGANTA (1997) acrescenta que a intensidade com que um jogador executa as ações no jogo está dependente da forma como as equipes jogam e da maneira como condicionam o ritmo de jogo. Portanto, ela é função da qualidade das opções tático-técnicas efetuadas pelo jogador no decurso do jogo. Refira-se que a literatura aponta a análise da dimensão tática como a dimensão que fornece os melhores indicadores do desempenho (Castelo, 2006; Cruz \& Tavares, 1998; Garganta, 1997, 2002; Garganta, Maia \& Basto, 1997; Garganta \& Pinto, 1998; Greco \& Chagas, 1992; Guia, Ferreira \& Peixoto, 2004; Mahlo, 1997; Oliveira, 2004; Paulis, 2000; Pinto, 1996; Riera, 1995b; Sisto \& Greco, 1995).

\section{Conclusão}

Com o presente estudo pretendeu-se caracterizar o processo de $\mathrm{AJ}$ realizado pelos treinadores da $1^{\mathrm{a}}$ liga portuguesa profissional de futebol nos seus clubes. Verificou-se que o "scouting" e a AJ da própria equipe são unanimemente utilizados e adquirem a sua pertinência ao nível da planificação estratégico-tática.

Apesar de se verificar um consenso em matéria de valorização atribuída à $\mathrm{AJ}$ da própria equipe para a consolidação do modelo de jogo, foram encontradas situações nas quais são operacionalizadas mudanças na forma de jogar em função das caraterísticas do adversário. Este paradoxo pode estar relacionado com a indistinção entre os conceitos de modelo de jogo e de sistema de jogo.

Foi também constatado que os treinadores são os protagonistas na $\mathrm{AJ}$ das suas equipes enquanto o "scouting" é delegado num elemento da equipe técnica exclusivamente designado para a análise de adversários.

No que diz respeito à frequência de realização da AJ, apesar de serem analisados um elevado volume de jogos, os meios utilizados são pouco sofisticados tendo em conta a disponibilidade de sistemas atualmente existentes, especificamente vocacionados para a análise do desempenho esportivo. 
Quanto aos eixos de análise que são utilizados, os treinadores preferem os que se relacionam com a dimensão tático-estratégica do jogo e desvalorizam os que se relacionam com a análise energéticofuncional (análise tempo-movimento).
Para futuras pesquisas recomenda-se a problematização da percepção dos treinadores face aos conceitos de modelo de jogo, sistema de jogo, tática e estratégia e o enfoque das razões que estão na base da não utilização de novas tecnologias de AJ.

\begin{abstract}
Characterization of match analysis process in Portuguese first football league teams: season 2005/2006

Nowadays, the competitive level achieved by professional football has required performance levels to increase highly. Match analysis is one of the tools that has been used to control performance. The aim of this work was to characterise match analysis process of 1st portuguese football league teams. The goals of this study were those of knowing: 1) the importance of match analysis; 2 ) the frequency of its accomplishment; 3 ) the professionals involved; 4) the instruments and systems used; and 5) the importance given to different axes of analysis. The sample was set up of sixteen coaches from the 1st Portuguese professional football 2005/06 league (89\% of the universe taken for study). To each coach it was applied a questionnaire previously ratified by eight specialists. The obtained results revealed that match analysis seems to acquire its pertinence in planning strategic and tactic dimensions. Agreeing with this idea, the elected dimensions of analysis are related with strategy and tactics. The less appreciated dimensions of analysis are related with time-motion analysis. It seems to be usual to use an instrument with predefined categories. The coach is the match analysis protagonist of his own team and confers the duty of scouting opponent teams to a member of the technical staff. The analysis systems used aren't sophisticated and only a minority admits to use computerised technologies. In summary, in the mentioned league the process of match analysis is sistematized and focuses mainly on tactical and strategic aspects of the game. However, despite being used instruments with predefined categories, the analysis systems used are unsophisticated.
\end{abstract}

UnITERMs: Football; Match analysis; Scouting; Performance; Game model.

\title{
Notas
}

1. GARGANTA (1997) define as variações como ações que, embora não representem regularidades ou invariâncias, assumem, pela sua imprevisibilidade, uma importância particular na história do jogo.

\section{Referências}

ALI, A. A statistical analysis of tactical movement patterns in soccer. In: REILLY, T.; LEES, A.; DAVIDS, K.; MURPHY, W.J. (Eds.). Science and football. London: E. \& FN Spon, 1988. p.302-8.

ANGUERA, M.; VILLASEÑOR, A.; LÓPEZ, J.; MENDO, A. La metodología observacional en el deporte: conceptos básicos. Lecturas: Educación Física y Deportes, Buenos Aires, n.24, 2000. Disponível em: <http://www.efdeportes.com/ efd24b/obs.htm>. Acesso em: 2 fev. 2005.

ARIEL, G. Complete application to sports analysis. Scholastic Coach, Pittsburg, aug. 1983.

BISHOVETS, A.; GADJIEV, G.; GODIK, M. Computer analysis of the effectiveness of collective technical and tactical moves of footballers in the matches of 1988 olympics and 1990 world cup. In: REILLY, T.; CLARYS, J.; STIBBE, A. (Eds.). Science and football II. London: E. \& FN Spon, 1991. p.203-5. 
BORRIE, A.; JONSSON, G.; MAGNUSSON, M. Temporal pattern analysis and its applicability in sport: an explanation and exemplar data. Journal of Sports Sciences, London, v.20, p.845-52, 2002.

CALLIGARIS, A.; MARELLA, M.; INNOCENTI, A. Il calico al computer: da Mexico '86 verso Italia '90. Roma: Società Stampa Sportiva, 1990.

CARLING, C. Applying match analysis to improve defending performance. Insight Live, [S.1.], 15 nov. 2005. . Choosing a computerised match analysis system. Insight, [S.1.],v.4, n.3, p.30-1, 2001.

CAROSIO, M. La observación de las clases de educación física como instrumento de ayuda profesional. Lecturas: Educación Física y Deportes, Buenos Aires, n.41, 2001. Disponível em: <http://www.efdeportes.com/efd41/obs.htm>. Acesso em: 22 fev. 2005.

CASTELO, J. Futebol: a organização do Jogo. [S.1.]: Edição do Autor, 1996.

Futebol: conceptualização e organização prática de 1100 exercícios de treino. Lisboa: Visão e Contextos, 2006. Futebol: modelo técnico-táctico do jogo. Lisboa: FMH Edições, 1994.

Futebol: organização dinâmica do jogo. Lisboa: FMH Edições, 2004. O exercício de treino. O acto médico versus o acto do treinador. Ludens, Lisboa, v.17, n.1, p.35-54, 2002.

CONTRERAS, M.; ORTEGA, J. La observación en los deportes de equipo. Lecturas: Educación Física y Deportes, Buenos Aires, n.18, 2000. Disponível em: <http://www.efdeportes.com/efd18a/dequipo.htm>. Acesso em: 2 fev. 2005.

CRUZ, J.; TAVARES, F. Notational analysis of the offensive patterns in cadets basketball teams. In: HUGHES, M.; TAVARES, F. (Eds.). IV World Congress of Notational Analysis of Sport. Porto: FCDEF-UP, 1998. p.112-9.

EOM, H.; SCHUTZ, R. Transition play in team performance of volleyball: A log-linear analysis. Research Quarterly for Exercise and Sport, Washington, v.63, n.3, p.261-9, 1992.

FRANKS, I. Use of feedback by coaches and players. In: REILLY, , T.; BANGSBO, J.; HUGHES, M.D. (Eds.). Science and football III. Cardiff: Spon Press, 1997. p.267-78.

FRANKS, I.; GOODMAN, D.; MILLER, G. Analyse de la performance: qualitative ou quantitative? Science du Sport, [S.1.], GY-1, p.1-7, 1983.

FRANKS, I.; McGARRY,T.The science of match analysis. In: REILLY,T.(Ed.). Science and soccer. London: E \& FN Spon, 1996. p.363-75. FRANKS, I.; McGARRY, T.; HANVEY, T. From notation to training: analysis of the penalty kick. Insight, [S.1.],v.3, p.24-5, 1999. GARCÍA, J. Balonmano: perfeccionamiento e investigación. Barcelona: INDE, 2000.

GARGANTA, J. A análise da performance nos jogos desportivos: revisão acerca da análise do jogo. Revista Portuguesa de Ciências do Desporto, Porto, v.1, n.1, p.57-64, 2001.

Analisar o jogo nos jogos desportivos colectivos: uma preocupação comum ao treinador e ao investigador. Horizonte, Lisboa, v.XIV, n.83, p.7-14, 1998. Análisis del juego en el fútbol: el recorrido evolutivo de las concepciones, métodos e instrumentos. Revista Entrenamiento Deportivo, A Coruña, v.XIV, n.2, p.5-14, 2000.

Fútbol: del juego al entrenamiento, del entrenamiento al juego. Training Fútbol, [S.1.], n.85, p.14-7, 2003.

Modelação táctica do jogo de futebol. 1997. Dissertação (Doutorado em Ciências do desporto) - Faculdade de Ciências do Desporto e de Educação Física, Universidade do Porto, Porto, 1997.

O treino da táctica e da técnica nos jogos desportivos à luz do compromisso cognição-acção. In: BARBANTI, V.; BENTO, J.O.; MARQUES, A.T., AMADIO, A.C. (Eds.). Esporte e atividade física: interação entre rendimento e saúde. São Paulo: Manole, 2002. p.281-306.

GARGANTA, J.; GRÉHAIGNE, J.F. Abordagem sistémica do jogo de futebol: moda ou necessidade. Movimento, Porto Alegre, v.V, n.10, p.40-50, 1999.

GARGANTA, J.; MAIA, J.; BASTO, F. Analysis of goal-scoring patterns in european top level soccer teams. In: REILLY, T.; BANGSBO, J.; HUGHES, M. (Eds.). Science and football III. Cardiff: Spon Press, 1997. p.246-50.

GARGANTA, J.; PINTO, J. O ensino do futebol. In: GRAÇA, A.; OLIVEIRA, J. (Eds.). O ensino dos jogos desportivos colectivos. 3. Ed. Porto: CEJD, 1998. p.95-135.

GODINHO, M. Controlo motor e aprendizagem: fundamentos e aplicações. 2. ed. Lisboa: FMH Edições, 2002.

GOWAN, G. Melhorar o rendimento pela análise do jogo. Futebol em Revista, Lisboa, 4. a série, n.21, p.35-40, 1987.

GRECO, P.; CHAGAS, M. Considerações teóricas da táctica nos jogos esportivos colectivos. Revista Paulista de Educação

Física, São Paulo, v.6, n.2, p.47-58, 1992.

GREHAIGNE, J.-F.; BOUTHIER, D.; DAVID, B. Dynamic-system analysis of opponent relationships in collective actions in soccer. Journal of Sports Sciences, London, v.15, p.137-49, 1997.

GRINVALD, R. Futbol: analisis funcional para la deteccion y formacion de talentos. Lecturas: Educación Física y Deportes, Buenos Aires, n.14, 1999. Disponível em: <http://www.efdeportes.com/efd14/talent.htm>. Acesso em: 2 fev. 2005. 
GROOM, R.; CUSHION, C. Coaches perceptions of the use of video analysis: a case study. Insight, [S.1.],v.3, n.7, p.56-58, 2004.

GROSGEORGE, B.; DUPUIS, P.; VEREZ, B. Acquisition et analyse de déplacements en sports collectifs. Science et Motricité, Ronchin, v.13, p.27-38, 1991.

GUIA, N.; FERREIRA, N.; PEIXOTO, C. A eficácia do processo ofensivo em futebol: o incremento do rendimento técnico-táctico. Lecturas: Educación Física y Deportes, Buenos Aires, v.79, n.10, 2004. Disponível em: <http://www. efdeportes.com/efd79/tatico.htm>. Acesso em: 30 nov. 2004.

HOTZ, A. Corrigir apenas o estritamente necessário, variar o mais possível: o treino da técnica elaborado em bases metodológicas. Treino Desportivo, Lisboa, v.6, p.22-36, 1999.

Notational analysis. In: REILLY, T. (Ed.). Science and soccer. London: E \& FN Spon, 1996. p.343-61.

HUGHES, M. So, what is performance analysis? 2005. Disponível em: <http://sukan.upm.edu.my/Buletin>. Acesso em: 17 ago. 2005. . Notation analysis in football. In: REILLY, T.; CLARYS, J.; STIBBE, A. (Eds.). Science and football II. London: E. \& FN Spon, 1991. p.151-9.

HUGHES, M.; BARTLETT, R. The use of performance indicators in performance analysis. Journal of Sports Sciences, Londo, v.20, p.739-54, 2002.

HUGHES, M.; CHURCHILL, S. Attacking profiles of successful and unsuccessful teams in Copa America 2001. In: REILLY, T.;. CABRI, J.; ARAÚJO, D. (Eds.). Science and football V. London: Routledge, 2005. p.219-24.

HUGHES, M.; FRANKS, I. Notational analysis of sport. 2nd ed. New York: Routledge, 2004.

JONSSON, G.; BJARKADOTTIR, S.; GISLASON, B.; BORRIE, A.; MAGNUSSON, M. Detection of real-time patterns in sports: interactions in Football. In: BAUDOIN, C. (Ed.). L'éthologie appliquée aujourd'hui. France: Levallois-Perret, 2003. v.3: Ethologie humaine.

JOYCE, J. News from the professional footballers association. Match analysis: a simple exercise? Insight, [S.l.], v.5, n.3, p.52-4, 2002. LIEBERMANN, D.; KATZ, L.; HUGHES, M.; BARTLETT, R.; McCLEMENTS, J.; FRANKS, I. Advances in the application of information technology to sport performance. Journal of Sports Sciences, London, v.20, p.755-69, 2002. LOPES, R. O scouting em futebol: importância atribuída pelos treinadores à forma e ao conteúdo da observação do adversário. 2005. Monografia (Licenciatura em Desporto e Educação Física) - Faculdade de Ciências do Desporto e de Educação Física, Universidade do Porto, Porto, 2005.

MAHLO, F. O acto táctico no jogo. 2. ed. Lisboa: Compendium, 1997.

MAIA. J. A modelação da performance desportivo-motora: uma necessidade do treinador, uma obrigação dos investigadores. Treino Desportivo, Lisboa, v.16, p.10-8, 2001.

MARQUES, F. Métodos de quantificação em desportos colectivos. Horizonte, Lisboa, v.65, p.183-9, 1995.

MARTINS, F. A periodização táctica segundo Vítor Frade: mais do que um conceito, uma forma de estar e de reflectir o futebol. 2003. Monografia (Licenciatura em Desporto e Educação Física) - Faculdade de Ciências do Desporto e de Educação Física, Universidade do Porto, Porto, 2003.

MARTINS, M. O scouting no basquetebol no escalão de cadetes. 2000. Monografia (Licenciatura em Desporto e Educação Física) - Faculdade de Ciências do Desporto e de Educação Física, Universidade do Porto, Porto, 2000.

McGARRY, T.; FRANKS, I. A stochastic approach to predicting competition squash match-play. Journal of Sports Sciences, London, v.12, p.573-84, 1994.

MORRISON, C. Why don't you analyze the way I analize? Journal of Physical Education, Recreation and Dance, Reston, v.71, n.1, p.22-5, 2000.

MOUTINHO, C. A importância da análise do jogo no processo de preparação desportiva nos jogos desportivos colectivos: o exemplo do voleibol. In: BENTO, J.; MARQUES, A. (Eds.). As ciências do desporto e a prática desportiva. Porto: FCDEF-UP, 1991. p.265-75.

MURTOUGH, J.; WILLIAMS, M. Using video in coaching. Insight, [S.I.], v.4, n.2, p. 38-9, 1999.

OLIVEIRA, J. Conhecimento específico em futebol: contributos para a definição de uma matriz dinâmica do processo ensino-aprendizagem/treino do Jogo. 2004. Dissertação (Mestrado em Ciências do Desporto) - Faculdade de Ciências do Desporto e de Educação Física, Universidade do Porto, Porto, 2004.

Especificidade, o pós-futebol do pré-futebol: um factor condicionante do alto rendimento desportivo. 1991. Monografia (Licenciatura em Desporto e Educação Física) - Faculdade de Ciências do Desporto e de Educação Física, Universidade do Porto, Porto, 1991.

Organização do jogo de uma equipe de futebol: aspectos metodológicos na abordagem da sua organização estrutural e funcional. In: JORNADAS TÉCNICAS DE FUTEBOL + FUTSAL DA UTAD, 2., Vila Real, 2003. Anais...Vila Real: UTAD, 2003. 
OLSEN, E.; LARSEN, O. Use of match analysis by coaches. In: REILLY, T.; BANGSBO, J.; HUGHES, M. (Eds.). Science and football III. Cardiff: Spon Press, 1997. p.209-19.

PACHECO, R. Segredos de balneário: a palestra dos treinadores de futebol antes do jogo. Camarate: Prime, 2005.

PAULIS, J. Observación y análisis de la acción de juego en fútbol. Lecturas: Educación Física y Deportes, Buenos Aires, n.22, 2000. Disponível em: <http://www.efdeportes.com/efd22b/julentd.htm>. Acesso em: 12 set. 2003.

PAULIS, J.; MENDO, A. Análisis diacrónico de la acción de juego en fútbol. Lecturas: Educación Física y Deportes, Buenos Aires, n.49, 2002. Disponível em: <http://www.efdeportes.com/efd49/diacro.htm>. Acesso em: 2 fev. 2005.

PEREIRA, N. Análise diacrónica da transição defesa-ataque em equipes de futebol de rendimento superior. 2005. Dissertação (Mestrado em Ciências do Desporto) - Faculdade de Ciências do Desporto e de Educação Física, Universidade do Porto, Porto, 2005.

PINTO, J. A táctica no futebol: abordagem conceptual e implicaçōes na formação. In: OLIVEIRA, J.; TAVARES, F. (Eds.). Estratégia e táctica nos jogos desportivos colectivos. Porto: CEJD, 1996. p.51-62.

QUEIROZ, C. Estrutura e organização dos exercícios de treino em futebol. Lisboa: Federação Portuguesa de Futebol, 1986. RIERA, J. Análisis de la táctica deportiva. Apunts: Educación Física y Deportes, Barcelona, n.40, p.47-60, 1995a.

. Estrategia, táctica y técnica deportivas. Apunts: Educación Física y Deportes, Barcelona, n.39, p.45-55, 1995b.

ROCHA, J. Scouting: a realidade dos sub-22. 1996. Monografia (Licenciatura em Desporto e Educação Física) - Faculdade de Ciências do Desporto e de Educação Física, Universidade do Porto, Porto, 1996.

RODRIGUES, L. A informática na observação dos jogos desportivos colectivos: um exemplo do voleibol. Treino Desportivo, Lisboa, v.26, p.59-61, 2004.

SAMPAIO, J. Análise do jogo em basquetebol: da pré-história ao Data Mining. Lecturas: Educación Física y Deportes, Buenos Aires, n.5, 1999. Disponível em: <http://www.efdeportes.com/efd15/datam.htm>. Acesso em: 19 mar. 2005.

SANTOS, J. O planeamento e periodização do treino em futebol: um estudo realizado em clubes da Superliga. 2006. Dissertação (Mestrado em treino de Alto Rendimento) - Faculdade de Motricidade Humana, Lisboa, 2006.

SILVA, J. Comportamento de uma equipe de futebol nos jogos realizados em sua casa e em casa do adversário: congruência com o modelo de jogo definido pelo treinador. 2002. Monografia (Licenciatura em Desporto e Educação Física) - Faculdade de Ciências do Desporto e de Educação Física, Universidade do Porto, Porto, 2002.

SILVA, M. A concepção de jogo: tarefa fundamental do treinador na preparação da equipe. In: TAVARES, F. (Ed.). Estudos CEJD2: estudo dos jogos desportivos: concepções, metodologias e instumentos. Porto: CEJD, 1999. p.99-102.

SISTO, F.; GRECO, P. Comportamento tático nos jogos esportivos coletivos. Revista Paulista de Educação Física, São Paulo, v.9, n.1, p.63-8, 1995.

\begin{tabular}{r|l} 
ENDEREÇO & \\
Pedro Silva & \\
Urbanização Encosta do Douro, Omega A, R/ C Esq & Recebido para publicação: 05/ 10/2009 \\
4420-134 - Gondomar - PORTUGAL & 1a. Revisão: 22/03/2010 \\
e-mail: silva.p.m@gmail.com & 2a. Revisão: 04/08/2010 \\
& 3a. Revisão: 27/ 10/2010 \\
& Aceito: 30/05/2011
\end{tabular}

Rev. bras. Educ. Fís. Esporte, São Paulo, v.25, n.3, p.441-53, jul./ set. 2011 • 453 